\section{Evidence-based sustainability}

I was surprised to read the editorial by Hébert and colleagues, which implied that Canada's health care system is financially sustainable when the evidence clearly shows that it is not. ${ }^{1}$ From 2000-2009, the federal government's revenue increased 22\%,,$^{2,3}$ and Ontario's revenue increased 49\%., ${ }^{4,5}$ Meanwhile, Ontario's health care costs increased by an unsustainable $88 \% \%^{4,5}$

With rapidly expanding expensive investigative tools, treatments and medications in conjunction with a free, comprehensive, universal health care system, both patients and physicians are being persuaded to perceive of "limitless essential services." Unfortunately, we do not have "limitless funds." There is no Canadian politician or leading physician who is prepared to state clearly that health services must be limited to those that are justified and tort reform must be introduced. Any provincial health costs that exceed perhaps $35 \%$ of provincial program spending should be raised from premiums and a portion of health care expenses based on a patient's ability to pay. Very fair, very Canadian.

\section{Ross McElroy MD}

Tavistock, Ont.

\section{References}

1. Hébert PC, Coutts J, Rosenfield D, et al. Sustainability is not the issue: Let's focus on quality. CMAJ 2011;183:885-6.

2. Department of Finance Canada. Annual financial report 2000-2001: 1. Fiscal years 2000-2001. Ottawa (ON): The Department; 2000. Available: www.fin .gc.ca/afr-rfa/2001/afr01_1-eng.asp (accessed 2011 July 25).

3. Department of Finance Canada. Annual financial report of the Government of Canada fiscal year 2009-2010. Ottawa (ON): The Department; 2010. Available: www.fin.gc.ca/afr-rfa/2010/report-rapport -eng.asp (accessed 2011 Aug. 26).

4. Ontario Ministry of Finance. Public accounts of Ontario. Financial statements, 2000-2001. Ottawa (ON): The Ministry; 2010. Available: www.fin.gov .on.ca/en/budget/paccts/2001/01_fs.html (accessed 2011 July 25)

5. Ontario Ministry of Finance. Public accounts of Ontario 2009-2010. Ottawa (ON): The Ministry; 2010. Available: www.fin.gov.on.ca/en/budget/paccts /2010/10_ar.html (accessed 2011 July 25).

\section{Oral contraceptives and risk of gallbladder disease}

Etminan and colleagues reported on an interesting study in which they found merely a little association between the use of oral contraceptives and gallbladder disease. ${ }^{1}$ This resembled the results of our recently completed observational study (unpublished data: 2011) in which the cumulative adjusted rate ratio (RR) was 1.01 (95\% confidence interval [CI] 0.97-1.12).

However, we found that oral contraceptives are an important contributor to gallbladder disease in patients with a body mass index (BMI) over 30 during drug administration (RR 1.46, 95\% CI 1.20-1.79). Etminan and colleagues gave information about the history of obesity but not the weight or BMI of the participants. They also did not perform subgroup analysis on the relationship between a history of obesity and gallbladder disease. Given large differences in diet and somatotypes in Occidental and Asian women, we think their study should have included a subgroup analysis based on demographic characteristics specifically for BMI or weight. Although we concluded from our study that women with a BMI less than 30 should not be concerned about gallbladder problems when taking oral contraceptives, those with a BMI over 30 should be careful.

We want to know whether Etminan and colleagues' retrospective study could obtain the same results as ours.

\section{FaZhou Wang PhD MD}

XiaoFeng Shen MD MPH

Department of Anesthesiology

XiRong Guo MD

\section{YuZhu Peng MD MPH}

Institute of Pediatrics

Nanjing Maternity and Child Health Care Hospital, Nanjing Medical University,

Nanjing, China

\section{Reference}

1. Etminan M, Delaney JAC, Bressler B, et al. Oral contraceptives and the risk of gallbladder disease: a comparative safety study. CMAJ 2011;183:899904.

CMAJ 2011. DOI:10.1503/cmaj.110-2065
We agree with Wang and colleagues that the risk of gallbladder disease with the use of oral contraceptives may be modified by different levels of BMI. ${ }^{1}$ Unfortunately, information on BMI was not available for our study. ${ }^{2}$ We agree that future research should examine this issue carefully.

\section{Mayhar Etminan PharmD MSc}

Department of Medicine, Faculty of Medicine, University of British Columbia, Vancouver, BC

\section{References}

1. Wang F, Shen X, Guo X, et al. Oral contraceptives and risk of gallbladder disease. CMAJ 2011;183: 1517.

2. Etminan M, Delaney JAC, Bressler B, et al. Oral contraceptives and the risk of gallbladder disease: a comparative safety study. CMAJ 2011;183:899-904.

CMAJ 2011. DOI:10.1503/cmaj.110-2066

\section{Absolute risk reduction a must}

After reading the article by Wells and colleagues on cardiac resynchronization therapy, ${ }^{1}$ I was not sure that the article had come from $C M A J$; it sounded like a salesperson had just dropped by and "detailed" me on the merits of putting a pacemaker/implantable cardioverter defibrillator into every patient with NYHA (New York Heart Association) class II disease.

To quote the authors, there was "no need for further clinical trials" because "the cumulative evidence is now conclusive" that there is "an unequivocal benefit ... in reducing all-cause mortality." Nowhere in the article is the absolute risk reduction mentioned. One would have to refer to Figures 2 and 3 to calculate it.

What happened to the peer review process at CMAJ? And where was the $C M A J$ editor? How can an article be published without the most relevant information in a trial — the absolute risk reduction?

I thought this was just an oversight, and I proceeded to the next excellent article in that issue by Eisenberg and associates. ${ }^{2}$ Again, no absolute risk reduction! How can I counsel patients 
on the hazards of cardiac imaging without this crucial information?

I humbly request that $C M A J$ include absolute risk reduction and/or increase in every research article published.

Robert Y. Shaw MD

Internal medicine, Vancouver, BC

\section{References}

1. Wells G, Parkash R, Healey JS, et al. Cardiac resynchronization therapy: a meta-analysis of randomized controlled trials. CMAJ 2011;183:421-9.

2. Eisenberg MJ, Afilalo J, Lawler PR, et al. Cancer risk related to low-dose ionizing radiation from cardiac imaging in patients after acute myocardial infarction. CMAJ 2011;183:430-6.

CMAJ 2011. DOI:10.1503/cmaj.110-2067

\section{Editor's response}

$C M A J$ is grateful for the reminder that what matters to a patient is the absolute risk. ${ }^{1}$ We should have made this easier for readers to find, especially in the second article to which Shaw refers.

The total mortality on optimal medical therapy was easy to see in Wells and colleagues' article; ${ }^{2}$ in Figure 2 it was $250 / 1013$, or $24.5 \%$. The absolute risk of cancer was less easy to find in Eisenberg and associates' article. ${ }^{3}$ One estimate might be 12020 cancers diagnosed in 82861 patients, as reported in the abstract; these occurred over an average follow-up time of five years according to the results, which suggests about 2.9 cases per 100 person years.
What these summary absolute risks hide, however, is that they may not be appropriate for an individual patient. Risk may vary with characteristics such as age, sex, severity of illness, comorbidity and family history. There is a long tradition of debate about whether to present research findings in terms of relative measures, which tend to be more stable between patient populations, or absolute measures, which have more immediate interpretability for clinicians and patients. ${ }^{4,5}$ We prefer to have both where possible, and we will make renewed efforts to remind authors to provide them.

\section{John Fletcher MB BChir MPH \\ Deputy Editor, Research, CMAJ}

\section{References}

1. Shaw RY. Absolute risk reduction a must. CMAJ 2011;183:1517.

2. Wells G, Parkash R, Healey JS, et al. Cardiac resynchronization therapy: a meta-analysis of randomized controlled trials. CMAJ 2011;183:421-9.

3. Eisenberg MJ, Afilalo J, Lawler PR, et al. Cancer risk related to low-dose ionizing radiation from cardiac imaging in patients after acute myocardial infarction. CMAJ 2011;183:430-6.

4. Schwartz LM, Woloshin S, Dvorin EL, et al. Ratio measures in leading medical journals: structured review of accessibility of underlying absolute risks. BMJ 2006;333:1248.

5. Naylor CD, Chen E, Strauss B. Measured enthusiasm: Does the method of reporting trial results alter perceptions of therapeutic effectiveness? Ann Intern Med 1992;117:916-21.

CMAJ 2011. DOI:10.1503/cmaj.110-2068

Some letters have been abbreviated for print. See www.cmaj.ca for full versions.

\section{CORRECTION}

\section{Folate status of the population in the Canadian Health Measures Survey}

In the February 8, 2011 issue of CMAJ, two errors occurred in the article by Colapinto and colleagues. ${ }^{1}$ The revised statements are below, with the correction in italics:

"Samples were thawed, diluted (1-in-26) with $0.5 \%$ ascorbic acid solution, allowed to incubate at room temperature for 18 minutes and then analyzed for folate using ..." (Methods section).

"Given the absence of folate deficiency in the general population and the apparent shift toward Canadians having high red blood cell folate concentrations ..." (Interpretation section).

$C M A J$ regrets the errors.

\section{Reference}

1. Colapinto CK, O'Connor DL, Tremblay MS. Folate status of the population in the Canadian Health Measures Survey. CMAJ 2011;183:E100-6. 